\title{
Do Discounts Enhance or Degrade IPOs Valuation Performance?
}

\author{
http://doi.org/10.21272/fmir.5(2).34-41.2021
}

Douaa Tizniti, ORCID: https://orcid.org/0000-0003-2708-4139

$\mathrm{PhD}$ Candidate, Faculty of Juridical, Economic and Social Sciences -Souissi, Mohammed V University of Rabat, Morocco

Mohammed Rachid Aasri, ORCID: https://orcid.org/0000-0001-5807-4641

Professor, Faculty of Juridical, Economic and Social Sciences -Souissi, Mohammed V University of Rabat, Morocco

\begin{abstract}
In the present study, we investigate the impact of discounts on the valuation performance of initial public offerings. Review of existing literature reveals that such valuation performance lacks examination in terms of discounts as most studies focus on valuation methods. Accordingly, we examine the valuation performance of initial public offerings before and after applying discounts. Whereby, underwriters apply a deliberate discount to fair value estimate before setting the final offer price. We assess the valuation performance of initial public offerings through bias and accuracy errors as well as explainability. When valuation errors are low, the valuation performance is deemed superior. Our sample consists of 39 initial public offerings conducted on the Moroccan stock exchange between 2004 and 2018. We use publicly available prospectus to collect necessary data. Our results reveal that discounts applied to fair value estimate when setting the final offer price reduce valuation errors. Consequently, discounts enhance the valuation performance of initial public offerings. In fact, both optimistic and pessimistic final offer price are closer to market price in comparison with optimistic and pessimistic fair value estimate. We conclude that if valuations conducted by underwriters are objective, discounts serve as a qualitative valuation to supplement the quantitative one. This qualitative valuation incorporates relevant information about market circumstances with regard to initial public offerings. This indicates the superior fundamental analysis underwriters are capable of performing. However, if valuations conducted by underwriters are subjective, then underwriters deliberately overestimates fair value estimate to justify applying discounts when setting the final offer price. Nonetheless, our study reveals that discounts are more than proportional to valuation optimism. Consequently, while discounts absorb this valuation optimism, they also set a valuation pessimism. In other words, discounts avoid overpricing initial public offerings, yet they result in underpricing them. Interestingly, we discover that although optimistic fair value estimate and pessimistic final offer price have approximate valuation errors, underwriters are more comfortable underpricing initial public offerings than overpricing them.
\end{abstract}

Keywords: IPO, underwriters, equity valuation, optimism, discount, underpricing

JEL Classification: G12, G24, G32.

Cite as: Tizniti, D., Aasri, M. R. (2021). Do Discounts Enhance or Degrade IPOs Valuation Performance? Financial Markets, Institutions and Risks, 5(2), 34-41. http://doi.org/10.21272/fmir.5(2).34-41.2021

Received: 8 April, 2021

Accepted: 5 May, 2021

Published: 25 June, 2021

Copyright: (C) 2021 by the authors. Licensee Sumy State University, Ukraine. This article is an open access article distributed under the terms and conditions of the Creative Commons Attribution (CC BY) license (https://creativecommons.org/licenses/by/4.0/)

\section{Introduction}

Initial Public Offerings (IPOs) mark a crucial step in a firm's lifespan, yet setting the offer price is beset by several challenges. IPOs valuation process as documented by Roosenboom (2012) starts with individual estimates produced by each valuation method used. Next, fair value estimate (FVE) is computed as the weighted average of all individual estimates. Then, preliminary offer price (POP) is computed by applying discount. Last, final offer price (FOP) is set by incorporating price updates. It is worth noting that these updates are applicable for bookbuilding offerings only. Consequently, POP and FOP are identical for fixed priced offerings as they are not subject to price updates, which is the case of our study. Most studies that examine 
IPOs valuation performance compare valuation errors, in terms of bias and accuracy as well as explainabiliy, using different valuation methods. When valuation errors are low, valuation performance is deemed superior. Empirical results show that popular valuation methods have similar valuation performance (Berkman et al., 2000; Courteau et al., 2006; Deloof et al., 2009; Kaplan \& Ruback, 1995; Roosenboom, 2012; Tutuncu, 2020). Deloof et al. (2009), Rasheed et al. (2018) and Roosenboom (2012) further investigate determinants of weights assigned to each valuation methods' individual estimates. Moreover, Deloof et al. (2009) and Kim \& Ritter (1999) examine FOP with regard to information incorporated by underwriters. However, although discount plays an important role in IPOs valuation, no study examined its effect on valuation performance. Surprisingly, even those studies for which discounts data are available focused on valuation methods (Deloof et al., 2009; Rasheed et al., 2018; Roosenboom, 2012; Tutuncu, 2020). This is mainly due to the public unavailability of discounts data (Tutuncu, 2020).

Through the literature review section, we identify a major research gap: IPOs valuation performance lacks examination in terms of discounts. Accordingly, our study focus on examining the impact of discounts on IPOs valuation performance. In other words, we examine whether discounts applied to FVE when setting FOP increase or rather decrease valuation errors. Our results reveal that discounts reduce valuation errors, which enhances IPOs valuation performance. We conclude that if valuations conducted by underwriters are objective, discounts serve as a qualitative valuation to supplement the quantitative one. This qualitative valuation incorporates relevant information about market circumstances with regard to IPOs. Additionally, these discounts indicate the superior fundamental analysis underwriters are capable of performing. However, if valuations conducted are subjective, then underwriters deliberately overestimates FVE to justify applying discounts when setting FOP. Nonetheless, our study reveals that discounts are more than proportional to valuation optimism. Consequently, while discounts absorb this valuation optimism, they also set a valuation pessimism, which results in IPOs underpricing. Interestingly, we discover that although optimistic FVE and pessimistic FOP have approximate valuation errors, underwriters are more comfortable underpricing IPOs than overpricing them. Our study makes two key contributions to the literature regarding IPOs valuation performance. First, we provide exclusive comparison of FVE and FOP in terms of bias and accuracy errors as well as explainability. Second, we show that discounts enhance IPOs valuation performance.

We believe that the Moroccan stock exchange is interesting to study as it is subject to fixed priced offerings only. Unlike bookbuilding offerings, fixed priced ones are not subject to price updates following investors' indications of interest before setting FOP. Instead, only discounts mark the last stage of IPOs valuation. Accordingly, this allows us to examine the impact of discounts on IPOs valuation performance by comparing between estimates pre-discounts (FVE) and estimates post-discounts (FOP). Such examination is possible because of the public availability of discounts following the modification of IPOs prospectus model in 2004.

The remainder of this paper is organized as follow: section 2 outlines related literature, section 3 presents methodology, section 4 reports results and develops discussions and section 5 highlights main conclusions.

\section{Related literature}

Studies investigating IPOs valuation performance mainly focus on valuation methods. Results show that Discounted Cash Flows (DCF), Dividend Discount Model (DDM) and Price-Earnings multiple (P/E) have similar accuracy errors (Berkman et al., 2000; Deloof et al., 2009; Kaplan \& Ruback, 1995; Roosenboom, 2012). Roosenboom (2012) additionally finds similar bias errors and explainability between these three methods. Contrarily, Tutuncu (2020) discovers that DCF is more biased and less accurate than multiples. Hence, underwriters must tradeoff between positive and negative aspects of each valuation method when valuing IPOs (Baker \& Ruback, 1999; Courteau et al., 2006; Kaplan \& Ruback, 1995). Furthermore, Deloof et al. (2009), Rasheed et al. (2018) and Roosenboom (2012) study determinants of weights assigned to individual estimates of each valuation methods. They conclude that the choice of underwriters depends on firm characteristics and aggregate stock market returns and volatility. Moreover, when examining FOP, Deloof et al. (2009) and Kim \& Ritter (1999) document its superiority in comparison with other estimates of IPOs valuation process. They explain that underwriters are capable of performing superior fundamental analysis by incorporating valuable information about IPOs demand collected during roadshows. These studies show that IPOs valuation performance have been examined considerably in terms of valuation methods, weights assigned to each method and price updates, yet not in terms of discounts. Actually, we were unable to find any study that assessed discounts' impact on IPOs valuation performance. Surprisingly, even those studies for which discounts data are available focused on valuation methods (Deloof et al., 2009; Rasheed et al., 2018; Roosenboom, 2012; Tutuncu, 2020). 
Generally, studies examining discounts in IPOs context are uncommon. This is mainly because of the unavailability of discounts data to the public. In fact, discounts data became available only recently in some European markets following the modification of regulation (Tutuncu, 2020). Most studies that have access to discounts data document that underwriters apply discounts when valuing IPOs before setting FOP (Cassia et al., 2004; Deloof et al., 2009; Paleari et al., 2014; Rasheed et al., 2018; Roosenboom, 2012; Tutuncu, 2020; Vismara et al., 2015). Deloof et al. (2009) discover that IPOs are deliberately underpriced by applying discounts before setting FOP. Through interviews, underwriters explain that they do so in order to present a good opportunity to all IPOs participants. Similarly, Roosenboom (2012) reports that underwriters apply discounts to FVE to reach POP when valuing bookbuilding IPOs. Part of this discount is recovered by positive price updates while the other part remains and contributes to IPO underpricing. Contrarily, Cassia et al. (2004), Paleari et al. (2014) and Vismara et al. (2015) document that discounts do not fully offset the optimistic bias and leaves IPOs overpriced. They explain that underwriters use discounts to make IPOs appear conservative. In fact, these studies reveal that underwriters select in a biased way peers in order to deliberately overestimate IPOs. Tutuncu (2020) shows that discounts depend mainly on optimistic valuation bias and do not lead to significant initial returns as expected by IPOs underpricing theories. Jeribi \& Jarboui $(2014,2015)$ document that underwriters use discounts to promote institutional investors. Tizniti \& Aasri (2021) on their part show that the discount applied to FVE when setting FOP is composed of two components: a justified part qualified as warranted discount and an unjustified part qualified as unwarranted discount. They document that warranted discounts enhance IPOs valuation performance while unwarranted discounts increase IPOs underpricing.

\section{Methodology}

Our sample consist of 39 IPOs conducted on the Casablanca stock exchange in Morocco from 2004 to 2018. Data about FVE, discounts, FOP and market prices (MP) were all hand collected from the Moroccan stock exchange's website. Accordingly, IPOs with missing FVE or discounts data were omitted from our study. Consistent with prior studies, we use both $1^{\text {st }}$ day and average $1^{\text {st }}$ month MP (Berkman et al., 2000; Deloof et al., 2009; Kim \& Ritter, 1999; Roosenboom, 2012; Tutuncu, 2020). Additionally, as suggested by Ljungqvist (2007), we do not base our study solely on $1^{\text {st }}$ day MP since the Moroccan exchange applies a volatility limit of $10 \%$ for newly listed equities. Because we found that both MP lead to the same conclusions, we refer to the average $1^{\text {st }}$ month MP, unless otherwise stated.

We compare between FVE and FOP, whereby the only difference between the two is discounts. This enables us to examine discounts' impact on IPO valuation performance. IPOs valuation performance is examined through bias and accuracy errors as well as explainability. In this context, the term error is not considered in its strict sense; rather it is a quantitative indication of the distance between estimates (FVE or FOP) and MP (Deloof et al., 2009). When valuation errors are low, valuation performance is deemed superior. Some papers compute valuation errors using the percentage measure ((estimates - MP) / MP) while other papers use the log measure (ln (estimates / MP) (Dittmann \& Maug, 2008). However, Dittmann \& Maug (2008) show that both error measures lead to the same ranking and error signs. It is worth noting that all of these papers assume either implicitly or explicitly a certain degree of market efficiency by considering that MP reflect the true value of equities and that they represent an appropriate standard for assessing IPOs valuation performance.

For the purpose of this study, bias error is computed in percent as the difference between FVE (FOP) and MP on MP, while accuracy error is the absolute value of bias error. However, as bias errors incorporate both positive and negative errors, they are subject to a compensation effect between optimistic and pessimistic valuations that might meddle with our study's conclusions. Hence, we also examine bias and accuracy errors by making a distinction between optimistic and pessimistic valuations. Whereby, optimistic valuations are estimates that are superior to MP and pessimistic valuations are estimates that are inferior to MP. This also enables us to account for eventual differences between optimistic and pessimistic estimates in terms of valuation errors. Unless otherwise stated, we construct our analysis based on the median instead of the mean as it is more robust to outliers. This is consistent with Dittmann \& Maug (2008) who suggest to report the median when using the percentage measure for two main reasons: first, the median percentage error is indicative of both the median and the mean log error and second, the median and the mean percentage error don't always lead to the same conclusions.

For explainabiliy we use cross-sectional ordinary least squares (OLS) univariate regression as previous studies (Berkman et al., 2000; Deloof et al., 2009; Rasheed et al., 2018; Roosenboom, 2012) : 


\section{Results and discussions}

Examining general valuation errors lead to conflicting results. Table 3 reveals that FVE $(-1.23 \%)$ are less biased than FOP (-12.53\%), which indicates that FVE are closer to MP in comparison with FOP. These results suggest that discounts applied to FVE when setting FOP increase valuation errors. Conversely, table 4 reveals that FOP (12.53\%) are more accurate than FVE (14.25\%), which indicates that FOP are closer to MP in comparison with FVE. These results suggest that discounts applied to FVE when setting FOP rather decrease valuation errors. Central tendency further supports this latter suggestion as FOP (56.41\%) have more central tendency than FVE (51.28\%). These results are also consistent with previous studies that reported FOP small errors in comparison with other estimates (Deloof et al., 2009; Kim \& Ritter, 1999). However, these studies account for the impact of price updates, instead of discounts as our study does, on IPOs valuation performance. Deloof et al. (2009) document that mean accuracy errors decrease from a range of $[22.1 \%-34.4 \%]$ when referring to individual estimates to a range of $[20.4 \%-22.1 \%]$ when referring to FOP.

We believe that the inconsistent results general valuation errors, bias and accuracy, lead to are due to the compensation effect between positive and negative errors as explained in the methodology section. Accordingly, examining specific valuation errors, bias and accuracy, lead to consistent results. Table 3 and 4 reveal that valuation errors are more pronounced for both optimistic $(16.82 \%)$ and pessimistic $(10.13 \%) \mathrm{FVE}$ in comparison with FOP (7.18\% and 15.39\%). Whereby, both optimistic and pessimistic FOP are less biased and more accurate than FVE. In other words, optimistic and pessimistic FOP are closer to MP in comparison with FVE. In fact, optimistic FVE errors (16.82\%) are superior than optimistic FOP errors (7.18\%). And although pessimistic FOP errors $(15.39 \%)$ are superior than pessimistic FVE errors $(10.13 \%)$, they do not exceed in extent optimistic FVE errors (16.82\%). These findings suggest that discounts applied to FVE when setting FOP decrease valuation errors, which enhances IPOs valuation performance. Univariate regression analysis documents consistent results. Table 5 reveals that FOP (Adj. $\mathrm{R}^{2}: 92.31 \%$ ) better explain MP variations than FVE (Adj. R2: 91.73\%). Both results are statistically significant at 1\% level and indicate that discounts applied to FVE when setting FOP allow better explanation of MP. Additionally, FOP intercept is closer to one (1.03) while slope is closer to zero (-0.01), in comparison with FVE (intercept 1.05 and slope -0.27). Slopes of both estimates are significant at $1 \%$ level while intercepts are insignificant. Berkman et al. (2000) and Roosenboom (2012) explain that slope should equal one and intercept zero if valuations are unbiased and accurate. Hence, results reveal that FOP are less biased and more accurate than FVE. These findings further indicate that discounts reduce valuation errors, which enhances IPOs valuation performance. Using the same regression model where FVE is the independent variable, Roosenboom (2012) documents a superior Adj. $\mathrm{R}^{2}$ $(94.39 \%)$ with an intercept of -0.124 and a slope of 1.017 .

Furthermore, we find that FVE are mainly optimistic (19/39 observations), while FOP is mainly pessimistic (33/39 observations). These findings reveal that valuations conducted by underwriters lead to FVE mainly optimistic with regard to MP. Additionally, underwriters seem to be conscious of this valuation optimism, hence they proceed into applying discounts. These discounts applied to FVE when setting FOP help absorb valuation optimism, which decreases valuation errors and enhances IPOs valuation performance. Nonetheless, these discounts are more than proportional to valuation optimism because they establishes a valuation pessimism, which results in IPOs underpricing. Similarly, specific valuation errors reveal that pessimistic FVE $(10.13 \%)$ are closer to MP than optimistic ones (16.82\%). As these optimistic FVE are more biased and less accurate, it seems justified to apply discounts to reduce the extent of valuation optimism. However, we curiously notice a shift in our results after applying discounts to FVE when setting FOP. Whereby, optimistic FOP (7.18\%) become closer to MP than pessimistic ones (15.39\%). These findings clearly indicate that discounts applied to FVE when setting FOP are not proportional to valuation optimism. Actually, as long as optimistic FVE cross the zero line and change to pessimistic FOP, we can clearly deduce that discounts applied are more than proportional. Consequently, this results in the underpricing of IPOs. This line of reasoning is consistent with the results of Tizniti \& Aasri (2021). In their study, Tizniti \& Aasri (2021) show that the discount applied to FVE when setting FOP is composed of two components, a justified part qualified as warranted discount and unjustified part qualified as unwarranted discount. They document that warranted discounts enhance IPOs valuation performance while unwarranted discounts increase IPOs underpricing. Surprisingly, it is worth noting that accuracy errors of optimistic FVE $(16.82 \%)$ are approximate to those of pessimistic FOP (15.39\%). We do not believe that this similarity is a mere coincidence. In fact, this suggests 
that underwriters seem to prefer pessimistic valuations to optimistic ones. In other words, underwriters are more comfortable underpricing IPOs rather than overpricing them. This is consistent with the expectation that underwriters have more to lose by overpricing IPOs than by underpricing them, for instance in terms of litigation and reputation (Hensler, 1995; Hughes \& Thakor, 1992; Ljungqvist, 2007; Tiniç, 1988).

This valuation optimism present in our findings is consistent with previous studies that reported deliberate optimism due to underwriters' discretion (Cassia et al., 2004; Derrien, 2005; Paleari et al., 2014; Roosenboom, 2012; Tutuncu, 2020; Vismara et al., 2015). Derrien (2005) finds that although French IPOs provide positive initial returns, they are overpriced at time of offering over their long run value. Cassia et al. (2004) show that Italian IPOs valuation conducted by analysts ignore multiples or exclude peers that make IPOs appear overvalued. Similarly, Roosenboom (2012) reveals that French IPOs valuation conducted by underwriters using different valuation methods results in optimistic estimates. Paleari et al. (2014) and Vismara et al. (2015) document that IPOs valuation performance depends on underwriters' biased selection of peers. These studies mutually explain that underwriters deliberately overvalue IPOs to justify applying high discounts when setting FOP. We argue that two different explanations can be provided regarding valuation optimism, depending on whether valuations conducted are objective or rather subjective. If valuations conducted by underwriters are objective, then FVE generated are optimistic merely from following guidelines of valuation methods used. Under such scenario, discounts applied to FVE when setting FOP serve as a qualitative valuation that supplements the quantitative one. This qualitative valuation indicates the superior fundamental analysis underwriters are capable of performing. As repeat player, underwriters collect relevant information about IPOs' market circumstances, particularly in terms of demand (Benveniste \& Spindt, 1989). Hence, discounts applied by underwriters prove to enhance IPOs valuation performance because they result in FOP closer to MP. This reasoning is consistent with Deloof et al. (2009) and Kim \& Ritter (1999). Both argue that underwriters play an important role in IPOs valuation, especially when setting FOP. Nonetheless, if valuations conducted by underwriters are subjective rather than objective, then FVE generated are intentionally optimistic. This reasoning is consistent with prior studies arguing that underwriters' discretion gives them the opportunity to apply discounts as they please when valuing IPOs (Cassia et al., 2004; Derrien, 2005; Paleari et al., 2014; Roosenboom, 2012; Tutuncu, 2020; Vismara et al., 2015). However, most of these studies report persistence of valuation optimism even after discounts, which is contrary to our findings.

\section{Conclusion}

In this paper, we investigate the impact of discounts on the valuation performance of IPOs in Morocco using publicly available prospectus. We discover that discounts applied to FVE when setting FOP reduce valuation errors, which enhance IPOs valuation performance. We conclude that if valuations conducted are objective, discounts serve as a qualitative valuation to supplement the quantitative one. This qualitative valuation incorporates relevant information about market circumstances with regard to IPOs. This indicates the superior fundamental analysis underwriters are capable of performing. However, if valuations conducted are subjective, then underwriters deliberately overestimates FVE to justify applying discounts when setting FOP. Nonetheless, our study reveals that discounts are more than proportional to valuation optimism. Consequently, while discounts absorb this valuation optimism, they also set a valuation pessimism, which results in IPOs underpricing. Interestingly, we discover that although optimistic FVE and pessimistic FOP have approximate valuation errors, underwriters are more comfortable underpricing IPOs than overpricing them.

Author Contributions: conceptualization: Tizniti, D., Aasri, M. R.; methodology: Tizniti, D.; validation: Tizniti, D., Aasri, M. R.; formal analysis: Tizniti, D.; investigation: Tizniti, D., Aasri, M. R.; resources: Tizniti, D.; data curation: Tizniti, D.; writing-original draft preparation: Tizniti, D.; writing-review and editing: Tizniti, D., Aasri, M. R.; supervision: Aasri, M. R.

\section{References}

1. Baker, M., \& Ruback, R. S. (1999). Estimating Industry Multiples. [Link]

2. Baker, M., Ruback, R. S., \& Wurgler, J. (2004). Behavioral Corporate Finance: A Survey. [CrossRef]

3. Benveniste, L. M., \& Spindt, P. A. (1989). How investment bankers determine the offer price and allocation of new issues. Journal of Financial Economics, 24(2), 343-361. [CrossRef] 
4. Berkman, H., Bradbury, M. E., \& Ferguson, J. (2000). The Accuracy of Price-Earnings and Discounted Cash Flow Methods of IPO Equity Valuation. Journal of International Financial Management \& Accounting, 11(2), 71-83. [CrossRef]

5. Cassia, L., Paleari, S., \& Vismara, S. (2004). The valuation of firms listed on the nuovo mercato: the peer comparables approach. [CroosRef]

6. Courteau, L., Kao, J. L., O'Keefe, T., \& Richardson, G. D. (2006). Relative Accuracy and Predictive Ability of Direct Valuation Methods, Price to Aggregate Earnings Method and a Hybrid Approach. [CrossRef]

7. Deloof, M., Maeseneire, W. D., \& Inghelbrecht, K. (2009). How Do Investment Banks Value Initial Public Offerings (IPOs)? Journal of Business Finance \& Accounting, 36(1-2), 130-160. [CroosRef]

8. Derrien, F. (2005). IPO Pricing in "Hot" Market Conditions: Who Leaves Money on the Table? The Journal of Finance, 60(1), 487-521. [CrossRef]

9. Dittmann, I., \& Maug, E. G. (2008). Biases and Error Measures: How to Compare Valuation Methods. [CrossRef]

10. Hensler, D. A. (1995). Litigation costs and the underpricing of initial public offerings. Managerial and Decision Economics, 16(2), 111-128. [CrossRef]

11. Hughes, P. J., \& Thakor, A. V. (1992). Litigation Risk, Intermediation, and the Underpricing of Initial Public Offerings. The Review of Financial Studies, 5(4), 709-742. [CrossRef]

12. Jeribi, A., \& Jarboui, A. (2014). Explaining deliberate IPO price discount evidence from the Tunisian stock market. International Journal of Business and Emerging Markets, 6(2), 121. [CrossRef]

13. Jeribi, A., \& Jarboui, A. (2015). The role of the ex ante uncertainty in the pre-listing IPO process: Evidence from the Tunisian stock market. International Journal of Economics and Business Research, 10(1), 46. [CrossRef]

14. Kaplan, S. N., \& Ruback, R. S. (1995). The Valuation of Cash Flow Forecasts: An Empirical Analysis. [CrossRef]

15. Kim, M., \& Ritter, J. (1999). Valuing IPOs. Journal of Financial Economics, 53(3), 409-437. [CrossRef]

16. Ljungqvist, A. (2007). IPO Underpricing: A Survey. [Link]

17. Paleari, S., Signori, A., \& Vismara, S. (2014). How Do Underwriters Select Peers When Valuing IPOs? Financial Management, 43(4), 731-755. [Link]

18. Rasheed, A., Sohail, M. K., Din, S.-U., \& Ijaz, M. (2018). How Do Investment Banks Price Initial Public Offerings? An Empirical Analysis of Emerging Market. International Journal of Financial Studies, 6(3), 1-19. [CrossRef]

19. Roosenboom, P. (2012). Valuing and pricing IPOs. Journal of Banking \& Finance, 36(6), 1653-1664. [CrossRef]

20. Tiniç, S. M. (1988). Anatomy of Initial Public Offerings of Common Stock. The Journal of Finance, 43(4), 789-822. [CrossRef]

21. Tizniti, D., \& Aasri, M. R. (2021). How discounts impact IPOs valuation performance and underpricing? A confrontation between warranted and unwarranted discounts. International Journal of Financial, Accounting, and Management, 3(1), 1-14. [CrossRef]

22. Tutuncu, L. (2020). Valuation and underpricing of Turkish IPOs. Journal of Business Economics and Management, 21(1), 157-179. [CrossRef]

23. Vismara, S., Signori, A., \& Paleari, S. (2015). Changes in underwriters' selection of comparable firms pre- and post-IPO: Same bank, same company, different peers. Journal of Corporate Finance, 34(C), 235-250. [CrossRef] 


\section{Appendix}

Table 1. Distribution of sample by type of shares offered and type of offering

\begin{tabular}{|c|c|c|c|c|c|c|}
\hline \multirow[b]{2}{*}{ Years } & \multicolumn{3}{|c|}{ Type of shares offered } & \multicolumn{2}{|c|}{ Type of offering } & \multirow[b]{2}{*}{ Total } \\
\hline & New shares & $\begin{array}{l}\text { Existing } \\
\text { shares }\end{array}$ & $\begin{array}{l}\text { New and existing } \\
\text { shares }\end{array}$ & Fixed price & Open price & \\
\hline 2004 & & 1 & & 1 & & 1 \\
\hline 2005 & 1 & 2 & & 1 & 2 & 3 \\
\hline 2006 & 3 & 3 & 2 & 6 & 2 & 8 \\
\hline 2007 & 2 & 5 & 2 & 5 & 4 & 9 \\
\hline 2008 & 2 & 1 & 2 & 3 & 2 & 5 \\
\hline 2010 & & 2 & & 2 & & 2 \\
\hline 2011 & 1 & 1 & 1 & 3 & & 3 \\
\hline 2012 & & 1 & & 1 & & 1 \\
\hline 2013 & 1 & & & 1 & & 1 \\
\hline 2014 & 1 & & & 1 & & 1 \\
\hline 2015 & & 2 & & 1 & 1 & 2 \\
\hline 2016 & & 1 & & 1 & & 1 \\
\hline 2018 & 1 & & 1 & 2 & & 2 \\
\hline Total & 12 & 19 & 8 & 28 & 11 & 39 \\
\hline
\end{tabular}

Source: Authors' computation.

Table 2. Distribution of sample by industry

\begin{tabular}{|l|c|c|}
\hline Industry & Number of IPOs & Percent (\%) \\
\hline Agri-food / production & 3 & $7.69 \%$ \\
\hline Banks & 1 & $2.56 \%$ \\
\hline Building \& Construction Materials & 3 & $7.69 \%$ \\
\hline Chemical & 1 & $2.56 \%$ \\
\hline Community Services & 1 & $2.56 \%$ \\
\hline Distributors & 5 & $12.82 \%$ \\
\hline Electricity & 1 & $2.56 \%$ \\
\hline Engineering \& Industrial equipment & 2 & $5.13 \%$ \\
\hline Finance companies \& other financial activities & 1 & $2.56 \%$ \\
\hline Hardware, Software \& IT Services & 6 & $15.38 \%$ \\
\hline Holding companies & 1 & $2.56 \%$ \\
\hline Hospitality and Leisure & 1 & $2.56 \%$ \\
\hline Insurance & 3 & $7.69 \%$ \\
\hline Mines & 1 & $2.56 \%$ \\
\hline Oil and gas & 1 & $2.56 \%$ \\
\hline Pharmaceutical industry & 2 & $5.13 \%$ \\
\hline Real estate investment and development & 3 & $7.69 \%$ \\
\hline Real estate investment trusts & 1 & $2.56 \%$ \\
\hline Transport & 1 & $2.56 \%$ \\
\hline Transport Services & 1 & $2.56 \%$ \\
\hline Total & 39 & $100 \%$ \\
\hline
\end{tabular}

Source: Authors' computation.

Table 3. Valuation bias errors

\begin{tabular}{|c|c|c|c|c|c|c|c|c|c|}
\hline \multicolumn{10}{|c|}{ Panel A: General valuation bias errors } \\
\hline & & $\mathrm{N}$ & Mean & Std. dev & $25^{\text {th }}$ per & $50^{\text {th }}$ per & $75^{\text {th }}$ per & Min & Max \\
\hline \multicolumn{10}{|l|}{$1^{\text {st }}$ day market price : } \\
\hline Fair value estimate & & 39 & $9.0143 * * *$ & 9.0384 & 3.1579 & $7.8598 * * *$ & 16.0247 & -9.0909 & 30.7692 \\
\hline Final offer price & & 39 & $\mid-6.6905 * * *$ & 4.6734 & -9.0909 & $\mid-9.0592 * * *$ & -3.7770 & -17.0732 & 10.7692 \\
\hline \multicolumn{10}{|c|}{ Average $1^{\text {st }}$ month market price : } \\
\hline Fair value estimate & & 39 & $|-0.9823 * * *|$ & 20.8015 & -12.0810 & $-1.2294 * * *$ & 16.8206 & -49.4483 & 32.3950 \\
\hline Final offer price & & 39 & $-15.2449 * * *$ & 16.9381 & -23.6975 & $-12.5272 * * *$ & -1.2294 & -57.1473 & 10.3994 \\
\hline \multicolumn{10}{|c|}{ Panel B: Specific valuation bias errors } \\
\hline & & $\mathrm{N}$ & Mean & Std. dev & $25^{\text {th }}$ per & $50^{\text {th }}$ per & $75^{\text {th }}$ per & Min & Max \\
\hline \multicolumn{10}{|l|}{$1^{\text {st }}$ day market price : } \\
\hline \multirow{2}{*}{ Fair value estimate } & Optimistic & 33 & $11.4309 * * *$ & 7.5095 & 6.8698 & $9.0079 * * *$ & 16.8939 & 0.8902 & 30.7692 \\
\hline & Pessimistic & 6 & $-4.2770 * * *$ & 3.0688 & -6.6667 & $-3.3569 * * *$ & -2.1951 & -9.0909 & -0.9956 \\
\hline \multirow{2}{*}{ Final offer price } & Optimistic & 3 & $3.8326 * * *$ & 6.0170 & 0.0233 & $0.7052 * * *$ & 10.7692 & 0.0233 & 10.7692 \\
\hline & Pessimistic & 36 & $\mid-7.5674 * * *$ & 3.3707 & $\begin{array}{l}-9.0909 \\
\end{array}$ & $\mid-9.0896 * * *$ & $\begin{array}{l}-5.1587 \\
\end{array}$ & -17.0732 & -0.5525 \\
\hline \multicolumn{10}{|c|}{ Average $1^{\text {st }}$ month market price : } \\
\hline \multirow{2}{*}{ Fair value estimate } & Optimistic & 19 & $16.2238^{* * *}$ & 8.4571 & 10.2345 & $16.8206^{* * *}$ & 19.3466 & 2.8105 & 32.3950 \\
\hline & Pessimistic & 20 & $-17.3281 * * *$ & 14.8442 & -30.7192 & $-10.1286^{* * *}$ & -5.8384 & -49.4483 & -1.2294 \\
\hline \multirow{2}{*}{ Final offer price } & Optimistic & 6 & $5.8903 * * *$ & 3.8161 & 2.3856 & \begin{tabular}{|c|}
$7.1850 * * *$ \\
\end{tabular} & 7.9759 & 0.2109 & 10.3994 \\
\hline & Pessimistic & 33 & $-19.0876^{* * *}$ & 15.4737 & -28.3298 & $-15.3873 * * *$ & -8.5920 & -57.1473 & -0.5909 \\
\hline
\end{tabular}

Notes: Except for N, all figures are in percent (\%). Significance is tested using a t-test for means and using a sign rank test for medians. ***, ** and * denote statistical significance at $1 \%, 5 \%$ and $10 \%$ levels.

Source: Authors' computation. 
Table 4. Valuation accuracy errors

\begin{tabular}{|c|c|c|c|c|c|c|c|c|c|c|}
\hline & & $\mathrm{N}$ & Mean & Std dey & Ctl tendency & $25^{\text {th }}$ ner & $50^{\text {th }}$ ner & $7^{\text {th }}$ ner & Min & Mar \\
\hline \multicolumn{11}{|l|}{$1^{\text {st }}$ day market price : } \\
\hline Fair value estimate & & 39 & $10.3303^{* * * a}$ & 7.4542 & 69.2308 & 4.6018 & $7.8697 * * * a$ & 16.0247 & 8902 & 30.7692 \\
\hline Final offer price & & 39 & $7.2801^{* * * a}$ & 3.6587 & 97.4359 & 4.6667 & $9.0883^{* * * a}$ & 9.0909 & .0233 & 17.0732 \\
\hline \multicolumn{11}{|c|}{ Average $1^{\text {st }}$ month market price : } \\
\hline Fair value estimate & & 39 & $16.7901^{* * * a \mathrm{a}}$ & 12.0153 & 51.2821 & 6.7753 & $14.2523 * * * a$ & 26.5875 & 1.2294 & 49.4483 \\
\hline Final offer price & & 39 & $17.0573^{* * * a \mathrm{a}}$ & 15.0604 & 56.4103 & 6.8372 & $12.5272^{* * * a}$ & 23.6975 & 2109 & 57.1473 \\
\hline \multicolumn{11}{|c|}{ Panel B: Specific valuation accuracy errors } \\
\hline & & $\mathrm{N}$ & Mean & Std. dev & Ctl. tedency & $25^{\text {th }}$ per & $50^{\text {th }}$ per & $75^{\text {th }}$ per & Min & Max \\
\hline \multicolumn{11}{|l|}{$1^{\text {st }}$ day market price } \\
\hline \multirow{2}{*}{ Fair value estimate } & Optimistic & 33 & $11.4309^{* * *}$ & 7.5095 & 63.6364 & 6.8698 & $9.0079 * *$ & 16.8939 & 8902 & 30.7692 \\
\hline & Pessimistic & 6 & $4.2770 * * *$ & 3.0688 & 100.0000 & 2.1951 & $3.3569 * *$ & 6.6667 & 9956 & 9.0909 \\
\hline \multirow{2}{*}{ Final offer price } & Optimistic & 3 & $3.8326^{*}$ & 6.0170 & 100.0000 & .0233 & .7052 & 10.7692 & .0233 & 10.7692 \\
\hline & Pessimistic & 36 & $7.5674 *$ & 3.3707 & 97.2222 & 5.1587 & 9.0896 & 9.0909 & .5525 & 17.0732 \\
\hline \multicolumn{11}{|c|}{ Average $1^{\text {st }}$ month market price : } \\
\hline \multirow{2}{*}{ Fair value estimate } & Optimistic & 19 & 16.2238 & 8.4571 & 42.1053 & 10.2345 & 16.8206 & 19.3466 & 2.8105 & 32.3950 \\
\hline & Pessimistic & 20 & 17.3281 & 14.8442 & 60.0000 & 5.8384 & 10.1286 & 30.7192 & 1.2294 & 49.4483 \\
\hline \multirow{2}{*}{ Final offer price } & Optimistic & 6 & $5.8903 * * *$ & 3.8161 & 100.0000 & 2.3856 & $7.1850^{* *}$ & 7.9759 & 2109 & 10.3994 \\
\hline & Pessimistic & 33 & $19.0876^{* * * *}$ & 15.4737 & 48.4848 & 8.5920 & $15.3873 * *$ & 28.3298 & .5909 & 57.1473 \\
\hline
\end{tabular}

Notes: Except for N, all figures are in percent (\%). Central tendency (Ctl. tendency) reports the percent of observations with an error accuracy inferior to $15 \%$. Significance is tested using a t-test for means and using a sign rank test for medians. ${ }^{\text {a }}$ Statistical significance using the natural log. ${ }^{* * *}, * *$ and $*$ denote statistical significance at $1 \%, 5 \%$ and $10 \%$ levels.

Source: Authors' computation.

Table 5. Valuation explainability of market prices

\begin{tabular}{|l|c|c|c|c|}
\hline Independent variables & \multicolumn{2}{|c|}{$1^{\text {st }}$ day market price } & \multicolumn{2}{|c|}{ Average $1^{\text {st }}$ month market price } \\
\hline Fair value estimate & $1.0327^{* * *}$ & & $1.0495^{* * *}$ & \\
\hline Final offer price & & $1.0161^{* * *}$ & & $1.0323^{* * *}$ \\
\hline Intercept & -.2869 & -.0275 & -.2740 & -.0083 \\
\hline Adj. $\mathrm{R}^{2}$ & $.9892^{* * *}$ & $.9962^{* * *}$ & $.9173^{* * *}$ & $.9231^{* * *}$ \\
\hline
\end{tabular}

Notes: OLS univariate regression with robust errors. ***, ** and * denote statistical significance at $1 \%, 5 \%$ and $10 \%$ levels.

Source: Authors' computation. 